\title{
INCUBATION OF PLATELET-RICH FIBRIN MATRIX WITH MESENCHYMAL STEM CELLS IMPROVES MATRIX STIFFNESS
}

\section{MIRTA H. REKSODIPUTRO', , GITA PRATAMA², BUDI WIWEKO ${ }^{2,5}$, EVANTHI KUSUMAWARDHANI ${ }^{3}$, DENISWARI RAHAYU ${ }^{3}$, RAISA NAULI ${ }^{3}$, VALENCIA JANE MARTIN ${ }^{3}$, NORMALINA SANDORA ${ }^{4,5 *}$}

${ }^{1}$ Department of Otorhinolaryngology-Head and Neck, Faculty of Medicine, Universitas Indonesia, Cipto Mangunkusumo Hospital, Jakarta, Indonesia, 'Department of Obstetrics and Gynaecology, Faculty of Medicine, Universitas Indonesia, Cipto Mangunkusumo Hospital,

Jakarta, Indonesia, ${ }^{3}$ Faculty of Medicine, Universitas Indonesia, Jakarta, Indonesia, ${ }^{4}$ Faculty of Medicine, Universitas Riau, Pekanbaru, Indonesia, ${ }^{5}$ Indonesian Medical Education and Research Institute, Faculty of Medicine, Universitas Indonesia, Jakarta, Indonesia Email: normalina.sandora@gmail.com

Received: 12 Oct 2019, Revised and Accepted: 17 Feb 2020

\section{ABSTRACT}

Objective: The platelet-rich fibrin matrix (PRFM) is condensed platelet-rich plasma (PRP) and should possess a comparable biomechanical property to the transplanted sites, for them to be physiologically functional. The aim of this study was to investigate the effect of human bone marrow mesenchymal stem cells (hBM-MSC) or human umbilical cord mesenchymal stem cells (hUC-MSC) on the biomechanical properties of PRFM.

Methods: PRFM was prepared by the gelation of PRP using $25 \mathrm{mmol} \mathrm{CaCl}_{2}$. The resulting coin-shaped PRFM pellets, $5 \mathrm{~cm}$ in diameter and $300 \mu \mathrm{m}$ thick, were directly seeded with hUC-MSC or hBM-MSC at 2,000 cells $\mathrm{cm}^{-2}$, followed by $24 \mathrm{~h}$ incubation at $37^{\circ} \mathrm{C}$ in $5 \%(\mathrm{v} / \mathrm{v}) \mathrm{CO}_{2}$ in air. The samples were then observed by scanning electron microscopy to determine the morphology of the matrix surface. The PRFM biomechanical properties were determined at a $10 \mathrm{~mm}$. $\mathrm{min}^{-1}$ failure rate using an MCT 2150 universal testing machine (AandD Co. LTD).

Results: SEM imaging of the surface of the PRFM seeded with hBM-MSC and hUC-MSC showed a cloudy layer that thickened over time. The elastin slope of the PRFM was significantly improved after seeding with hBM-MSC and hUC-MSC when compared with unseeded PRFM (p<0.002, $\left.\mathrm{R}^{2}=0.983\right)$. Both cell types elicited similar biomechanical effects $(\mathrm{p}=0.99)$.

Conclusion: PRFM seeded with hBM-MSC or hUC-MSC showed significantly increased elasticity.

Keywords: Platelet-rich fibrin matrix, Mesenchymal stem cells

(C) 2020 The Authors. Published by Innovare Academic Sciences Pvt Ltd. This is an open access article under the CC BY license (http://creativecommons.org/licenses/by/4.0/) DOI: http://dx.doi.org/10.22159/ijap.2020.v12s3.39604

\section{INTRODUCTION}

Wound healing after open injury or surgical procedures is challenging, and many materials and techniques have been evaluated for their ability to enhance and accelerate complete healing [1]. Normally, fibrin clot is formed in an open wound. It is highly elastic and viscous to stop bleeding and maintains hemostasis by forming a mesh that traps platelets [2].

Platelets are rich in growth factors, including platelet-derived growth factor (PDGF), transforming growth factor (TGF-b), vascular endothelial growth factor (VEGF), basic fibroblast growth factor (bFGF) and insulin-like growth factor (IGF) [3, 4]. In addition, platelets release coagulation factors, serotonin, histamine, endostatin and hydrolytic enzymes [4]. Platelets can also be used to isolate a platelet-rich fibrin matrix (PRFM), a second-generation platelet fraction derived from platelet-rich plasma (PRP) obtained by centrifugation of whole blood. The PRP contains a 6-to 8-fold higher growth factor concentration than whole blood and can form the PRFM fibrin network following the addition of $\mathrm{CaCl}_{2}$ [5]. The growth factors in the PRFM are released slowly between 7 and $14 \mathrm{~d}$.

PRFM is used across the globe in various procedures, including orthopedic, cardiothoracic, vascular, general, and plastic surgeries. PRFM serves many different clinical needs due to its favorable promotion of healing, simple processing and ease of suturing to surrounding tissues. The natural fibrin framework in PRFM is thought to protect the growth factors from proteolysis. For clinical use, autologous sources for PRP are favored to eliminate disease transmission from donors. Naturally, the transplanted matrix will be invaded by the surrounding cells. While matrix stiffness is very important for its application that dictates the choice of biomaterial to replace a given tissue, nonetheless, until recently, no study has explored the biomechanical properties of PRFM after infiltrated with cells.

Mechanical forces are important drivers of cellular growth and development, but mechanical overload leads to tissue injury [6]. A mechanical force or load that causes a material to change its shape is termed mechanical stress, symbolized by the Greek letter sigma $(\sigma)$, and is defined as the force per unit area within a material $(\sigma=\mathrm{F} / \mathrm{A})$. Mechanical stress is similar to the concept of pressure and has the same units $\left(\mathrm{N} . \mathrm{m}^{-2}\right)$, where one $\mathrm{N} . \mathrm{m}^{-2}$ is equal to one Pascal $(\mathrm{Pa})$ of stress or pressure.

PRFM, once fully polymerized, is quite stiff, with an elastic modulus of $937.3 \pm 314.6 \mathrm{kPa}$, stress at break value of $1476.0 \pm 526.3 \mathrm{kPa}$, and an elongation at break value of $146.3 \pm 33.8 \%$, as cited by Lucarelli and colleagues [7]. These values represent a stiffness equivalent to about half that of intact human skin [8]. Human BM-MSC seeded on decellularized tendon had increased matrix ultimate tensile stress after $7 \mathrm{~d}$ incubation with $6 \%$ strain [9]. The aim of the present study was to investigate the PRFM biomechanics, including the elastic modulus, ultimate tensile stress and ultimate tensile strain, before and after incubation of prepared PRFM with human bone marrow mesenchymal stem cells (hBM-MSC) or human umbilical cord mesenchymal stem cells (hUC-MSC).

\section{MATERIALS AND METHODS}

Upon receipt of ethical approval (no 78/UN2. F1. D/PA/PPM. SIPP.00.02/2018), four blood donors were screened for human immunodeficiency virus [10], hepatitis $B$, hepatitis $C$ and cytomegalovirus infections. All four donors provided signed informed consent for participation in the study. Peripheral blood samples $(8 \mathrm{ml})$ were withdrawn from each donor for the preparation of PRFM.

\section{Matrix preparation}

Platelet-rich plasma was isolated using RegenKit®-BCT (Regenlab), followed the manufacturer's instructions. Briefly, the $8 \mathrm{ml}$ of peripheral blood in the collection tube was centrifuged at $1500 \mathrm{~g}$ for $10 \mathrm{~min}$, and the resultant plasma supernatant and platelet sediment were inverted and mixed 10 times. A $7 \mathrm{ml}$ volume was removed, 
placed in a sterile $100 \mathrm{ml}$ flask (Falcon Biologics), and sterile 25 mmol $\mathrm{CaCl}_{2}$ was added to gel the PRP. The sample was then centrifuged at $3500 \mathrm{~g}$ for $10 \mathrm{~min}$ to form a coin-shaped PRFM pellet about $5 \mathrm{~cm}$ in diameter and 300-400 $\mu \mathrm{m}$ thick. Each PRFM was cut in half, and each half was placed into a well of a 6-well plate. Eight 6well plates were prepared: four for hUC-MSC and four for hBM-MSC Each plate group was labelled for each day of validation (Day 1, Day 5, Day 10 and Day 13). Each plate had three wells with seeded PRFM and one well for an unseeded PRFM control. A separate well was used as a cell culture control (cells only) and another well for a culture medium control (culture medium only).

\section{Preparation of the cells}

Human UC-MSCs and the hBM-MSCs were obtained from the Stem Cells and Tissue Engineering Department in our university. The hUCMSC were obtained at passage 2, while the hBM-MSC were at passage 1. Both hBM-MSC and hUC-MSC expressed CD 73, CD 90 and CD 105 but did not express Lin. Both cell types were expanded in alphamodified Eagle's medium ( $\alpha$-MEM) (Gibco, Germany), supplemented with $100 \mathrm{U} \quad \mathrm{ml}^{-1}$ penicillin/streptomycin (Hybri-Max ${ }^{\mathrm{mm}}$, Sigma, Germany), 2 mmol L-glutamine (Gibco, Germany), 1\% (v/v) amphotericin B (Gibco, Germany), 1\% (v/v) heparin (Sigma, Germany) and $10 \%(\mathrm{v} / \mathrm{v})$ platelet-rich plasma (PRP) by incubation at $37{ }^{\circ} \mathrm{C}$ in $5 \%$ $(\mathrm{v} / \mathrm{v}) \mathrm{CO}_{2}$ in air. The culture medium was refreshed every three days The cells were passaged at $85 \%$ to $90 \%$ confluence, trypsinised using $0.25 \%$ trypsin in 1 mmol EDTA (Invitrogen, Karlsruhe, Germany) and then re-plated at the density of 2,500 cells $\mathrm{cm}^{2}$. Cells were expanded from passage 2 to 4

\section{Seeding preparation}

The matrix for seeding was preconditioned overnight and then directly seeded as described previously [11] with hBM-MSC or hUC-MSC at a seeding density of 2,000 cells $\mathrm{cm}^{-2}$ in $100 \mu$ culture medium. The cells were left for $2 \mathrm{~h}$ and then then flooded with $3 \mathrm{ml}$ culture medium and incubated at $37^{\circ} \mathrm{C}$ in $5 \%(\mathrm{v} / \mathrm{v}) \mathrm{CO}_{2}$ in air for $24 \mathrm{~h}$.

At the end of each incubation day, each specimen was cut into four pieces. The sample for biomechanical testing was shaped into a 5 $\mathrm{mm}$ wide $\times 20 \mathrm{~mm}$ long rectangle, placed on sterile filter paper soaked in PBS and tested within $2 \mathrm{~h}$. The sample for SEM was treated as described elsewhere. Briefly, the specimen was cut into a $5 \times 5$ mm square $(n=3)$, soaked in $3 \%$ glutaraldehyde in phosphatebuffered saline (PBS) for $2 \mathrm{~h}$ at $4{ }^{\circ} \mathrm{C}$, followed by 20 min PBS washes at $4{ }^{\circ} \mathrm{C}$ and post fixing in $2 \%$ osmium tetroxide in PBS. After dehydration in a graded ethanol series at $4{ }^{\circ} \mathrm{C}$, the specimen was mounted and coated with a gold/palladium alloy [12].

\section{Sample analysis}

Specimens prepared for SEM were cut into $5 \times 5 \mathrm{~mm}^{2}$ pieces, soaked in $2.5 \%(\mathrm{v} / \mathrm{v})$ glutaraldehyde (Sigma, Germany) in PBS for $2 \mathrm{~h}$, followed by PBS washes ( 3 times, 20 min each). The samples were then fixed in $2 \%$ osmium tetroxide in PBS, washed again with PBS, and dehydrated in a graded ethanol series at $10 \mathrm{~min}$ steps at $4{ }^{\circ} \mathrm{C}$. The SEM specimens were mounted with graphite, coated with gold/palladium alloy and visualized using an LS2 h M SEM microscope.
A Dynatron USM-500 N load cell (AandD Co. Ltd, Switzerland) and an MCT 2150 testing bench were used to measure the PRFM biomechanical properties after $24 \mathrm{~h}$ incubation with and without seeding with hBM-MSC and hUC-MSC $(n=3)$; the samples without seeded cells were used as a control. Samples were prepared as $3 \mathrm{~cm}$ (length) $\times 5 \mathrm{~mm}$ (width) rectangles measured using Vernier callipers (Mitutuyo, Japan). They were placed on filter paper wetted with PBS and tested within $2 \mathrm{~h}$. Each specimen was fixed onto the grips, with linen placed between the grips to protect the samples from being cut during the test. The failure rate was set at $10 \mathrm{~mm} \mathrm{~min}^{-1}$. Only samples with a failure at the mid-point were included in calculations.

\section{Data analysis}

Raw data recorded from the Dynatron USM, with units of force $(\mathrm{N})$, extension $(\mathrm{mm})$ and time (s), were exported to Microsoft Excel (version 2013, Microsoft Corporation). The data were then converted to engineering stress $(\sigma)$ and engineering strain $(\varepsilon)$ responses of each sample by normalizing the initial sample dimensions. The calculation was performed manually as follows:

The engineering strain $(\varepsilon)$ was the percentage of the sample elongation $(\Delta l)$ divided by the original sample (gauge) length (the sum of $(l)$ and elongation $(\Delta l))$ :

$$
\text { Engineering strain }(\mathcal{E})=\frac{\Delta \mathrm{l}(\mathrm{mm})}{\mathrm{l}(\mathrm{mm})+\Delta \mathrm{l}(\mathrm{mm})}
$$

The stress-strain value was plotted as the stress-strain slope (fig. 1), and the behavior of each specimen was characterized using five parameters: ultimate tensile strength (UTStress) $\left(\sigma_{\text {fail }}\right)$, ultimate tensile strain (UTStrain) ( $\left.\varepsilon_{\text {fail }}\right)$, elastin phase slope $\left(E_{\text {elas }}\right)$, collagen phase slope $\left(E_{\text {coll }}\right)$ and the relaxation modulus (Young's modulus, $E(t)$ ).

The UTStress ( $\sigma_{\text {UTS }}$ ) was determined as the initial point of the sample to reach the highest stress value, and the UTStrain (EuTs) was determined as the strain value at which the sample began to fail. The collagen phase slope $\left(E_{\text {coll }}\right)$ was determined by fitting a linear trend line between two points selected manually in the linear part of the curve between the initial toe of the curve and the yield point of the failure region. The elastin phase slope was determined by the area underneath the stress strain curve, up to a strain limit of 0.05 because the sample size was relatively small. This limit for fascicles was similar to the value cited by others. The strain limit at 0.05 was obtained and the elastin slope was achieved by integrating the strain between zero and 0.05 to determine the area. The Young's modulus $E(t)$ was calculated using the following equation:

$$
\mathrm{E}(\mathrm{t})=\frac{\text { Engineering Stress }(\sigma)(\mathrm{MPa})}{\text { Engineering Strain }(\mathcal{E})}
$$

Where $\sigma$ was the engineering stress and the $\varepsilon$ was the engineering strain, as stated above. The data for the decellularized and the native tendon specimens were analyzed using two-sample Student's t-tests to compare the two means of each biomechanical parameter (the variances of each group assumed homoscedasticity, as heteroscedastic has not affected testing sensitivity when testing an equal sample size). Data are presented as the mean $(n=6) \pm 95 \%$ C. I.

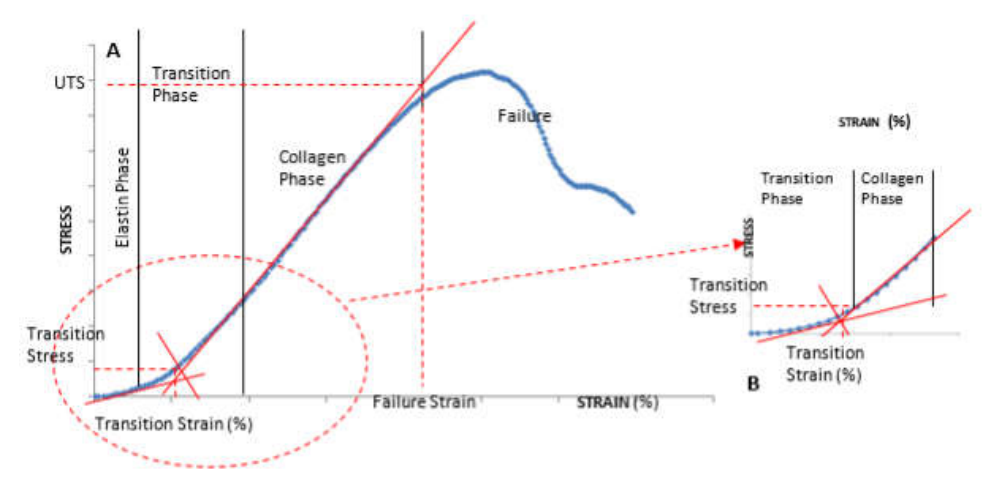

Fig. 1: Stress-strain curve of a native tendon. (A) The stress-strain slope with the biomechanical parameters. (B) The toe region highlighted from the whole stress-strain curve 

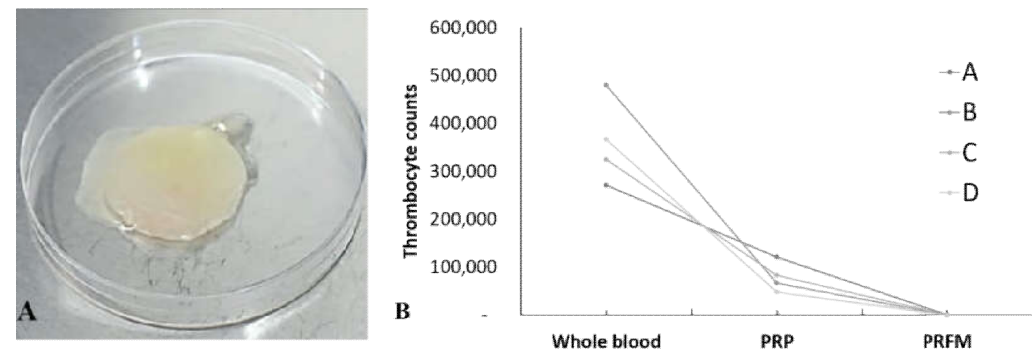

Fig. 2: Platelet-rich fibrin matrix (PRFM), (A) macroscopic, with a coin shape, prepared immediately before seeding with stem cells. (B) Thrombocyte counts

The SEM analysis (fig. 3) revealed a layer of cells on the surface after the $24 \mathrm{~h}$ incubation. This layer thickened as the incubation days progressed and eventually fully coated the matrix. This coating was observed with both hBM-MSC and hUC-MSC. No difference was seen between the two groups. By contrast, the SEM images of the unseeded matrix showed fibers aligned across the matrix.
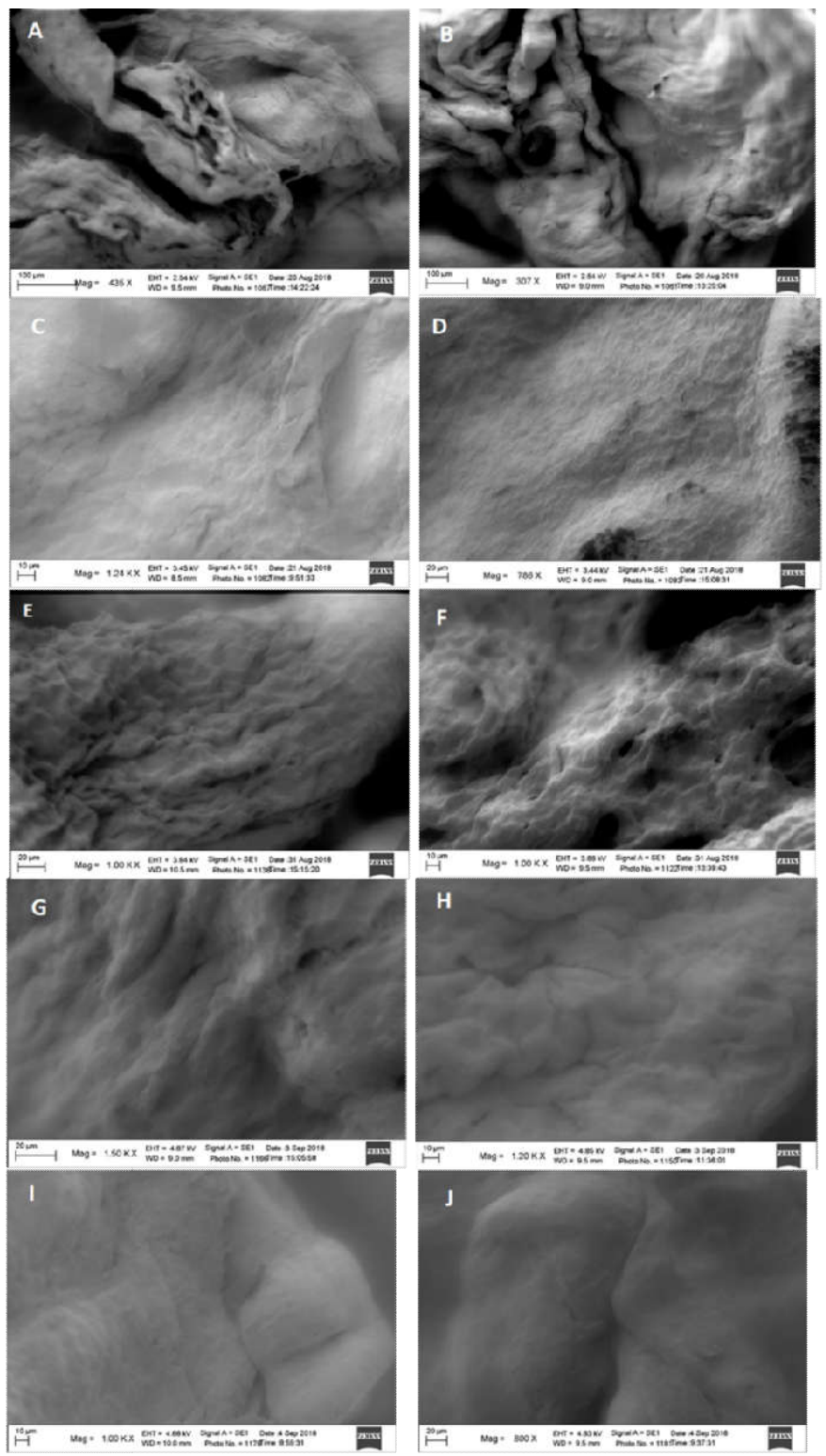

Fig. 3: Scanning electron microscopy images of the platelet-rich fibrin matrix (PRFM) (A, B) and PRFM after seeded with (C, E, G, I) hBMMSC and (D, F, H, J) hUC-MSC. (C, D) Day 1, (E, F) Day 5, (G, H) Day 10 and (I, J) Day 13 incubation. Images were captured using LSM 800; scale bars are indicated in each image 
The biomechanical analysis of the PRFM with and without cells is summarized in table 1 . As shown in fig. 4, the elastin slope was significantly improved by seeding the PRFM with hBM-MSC or hUCMSC $(\mathrm{p}<0.01)$. The Young's modulus was two-fold higher for the PRFM seeded with hBM-MSC than with hUC-MSC or for the unseeded PRFM control. The Young's modulus was similar for the PRFM seeded with hUC-MSC and the unseeded control. No differences were noted among the three groups for any other biomechanical parameters.

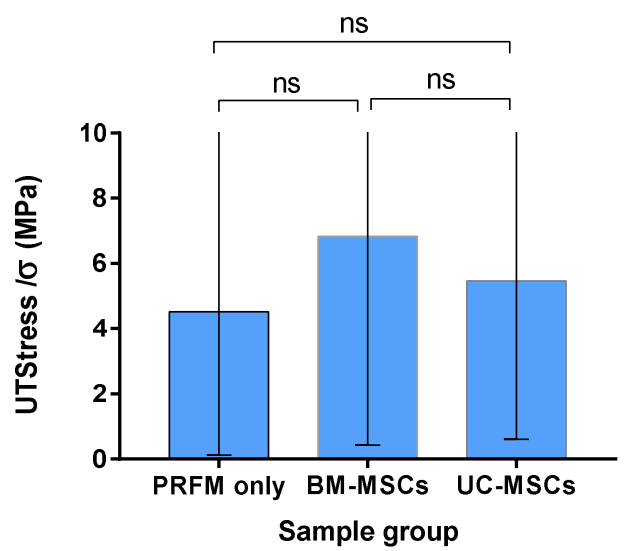

A

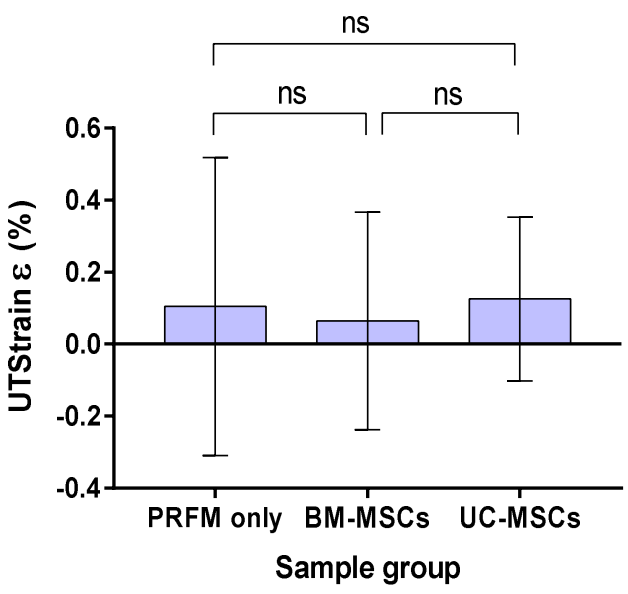

C

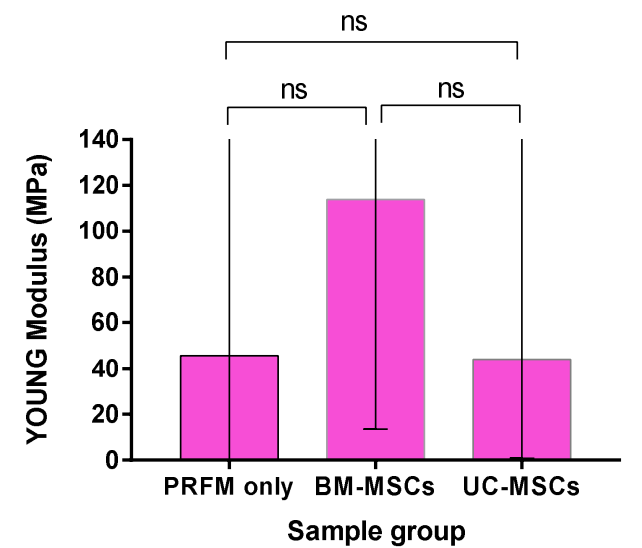

B

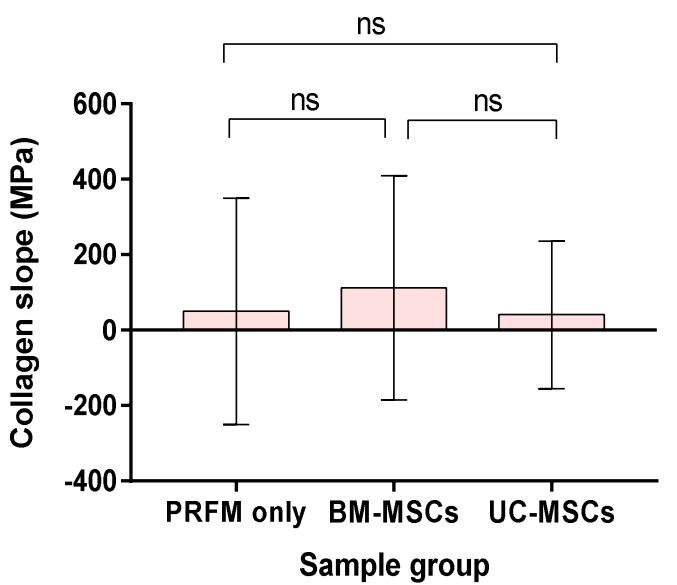

D

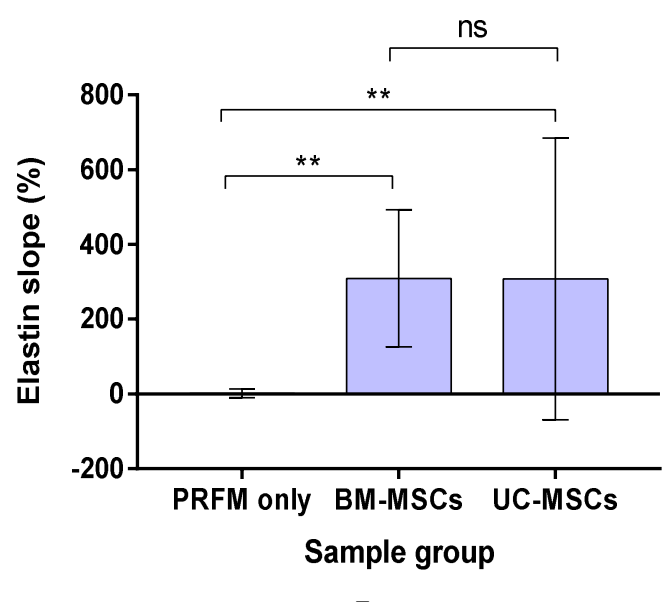

E

Fig. 4: Biomechanical analysis of PRFM only and PRFM after seeding with hBM-MSC and hUC-MSC for 24 h. (A) Ultimate tensile stress, (B) Young's modulus, (C) Ultimate tensile strain, (D) collagen slope, and (E) elastin slope. Data were analysed using one-way ANOVA, and differentiated using Tukey analysis; a p value $<0.05$ was considered statistically significant 
Table 1: Distribution of biomechanical properties of PRFM before and after seeding with UC-MSC and BM-MSC, Data are presented as mean $(n=3) \pm 95 \%$ C. 1 .

\begin{tabular}{llll}
\hline Biomechanical properties & PRFM & hBM-MSC/PRFM & hUC-MSC/PRFM \\
\hline Elastin slope (MPa) & $1.3 \pm 1.99$ & $297.18 \pm 51.13$ & $308.13 \pm 60.28$ \\
Collagen/Ecoll & $54.79 \pm 50.37$ & $107.87 \pm 49.9$ & $41.934 \pm 31.33$ \\
PSD (MPa) & $-17.25 \pm 124.7$ & $1246.54 \pm 2777.72$ & $2.12 \pm 41.55$ \\
$\sigma$ UTStress (MPa) & $4.97 \pm 2.798$ & $7.1 \pm 3.06$ & $5.48 \pm 1.96$ \\
$\varepsilon$ UTStrain (\%) & $0.106 \pm 0.067$ & $0.06 \pm 0.04$ & $0.12 \pm 0.05$ \\
Young Modulus (MPa) & $57.79 \pm 60.92$ & $120.29 \pm 42.46$ & $47.45 \pm 29.29$ \\
\hline
\end{tabular}

\section{DISCUSSION}

PRFM consists of bundles of monomeric fibrin that are able to undergo appreciable extension [2, 13]. Its biomechanical properties are determined by the number of fibre monomers and how they are braided together [2]. The mechanical behavior of the entire fibrin gel is determined by the number and packing arrangements of doublestranded half-staggered protofibrils that allow orientation, stretching bending and buckling [14]. However, many studies of fibrin matrix (PRFM) biomechanics have reported a weak capacity. As many studies showed cells improved matrix biomechanical properties; therefore, the focus of the present study was to investigate the biomechanical properties of PRFM before and after incubation with MSC.

Cell populations in a scaffold are essential for the process of scaffold morphogenesis, tissue matrix turnover and the wound healing process $[15,16]$. In the present study, hBM-MSC were used, as these cells have been reported to contribute to the healing process, especially in tendon repair. The hUC-MSC was also studied because they have potential future uses in wound healing. The hUC-MSC are known to release of growth differentiation factor GDF-11, which induces human dermal fibroblast proliferation, migration, and extracellular matrix (ECM) production [17]. The hUC-MSC are also reported to differentiate into hepatocytes, as indicated by their expression of the albumin gene after $14 \mathrm{~d}$ of incubation with hepatocyte growth factor (HGF) and fibroblast growth factor 4 (FGF4) [18]. Another study has also reported that granules of fibrin matrix improved the re-implantation of avulsed incisors in dogs after the incisor was overlaid with the granules and periodontal ligament stem cells. The periodontal area showed low inflammation and the layer formed periodontal-like tissues [19]

In the present in vitro study, PRFM was degraded after $5 \mathrm{~d}$ of incubation with cells, but it had retracted only by half after $24 \mathrm{~h}$. By contrast, the unseeded control PRFM was no longer identifiable in the plate after $3 \mathrm{~d}$ of incubation. This degradation of PRFM may have been due to the fibrinolysis process [20], which can be blocked by adding a sealant agent, such as aprotinin, tranexamic acid [21], or human Kunitz-type proteinase inhibitor, to the fibrin matrix [22]. The Kunitztype proteinase is superior to aprotinin as it is derived from human sources and can improve the fibrin matrix longevity by up to $50 \%$ through a 10-fold inhibition of plasmin-mediated fibrinolysis [22] Improvements in PRFM durability may be required in future studies.

PRFM is a weak biomaterial that degrades in a fast rate. In the present study, the PRFM after seeded with cells had contracted up to $70 \%$ of their original size after $5 \mathrm{~d}$ incubation and faded after $10 \mathrm{~d}$, suspected they had been fully degraded. Therefore, this study had no biomechanical analyses conducted on the Day 5, 10 and 13 samples in the present study, as the sample size of the Day 5 were insufficient, and the Day 10 or the Day 13 samples had completely diminished. In addition, only the $24 \mathrm{~h}$ samples had sufficient retention of their shape and size to allow mounting in the grips for biomechanical testing. Other biomechanical analyses using the rheology test would be more sensitive for investigating gel formation, as it able to determine the characteristics of a single fibre.

The culture of the PRFM with h-BM-MSC and hUC-MSC significantly improved the PRFM elastin slope $(297.18 \pm 51.13 \mathrm{MPa}$ and $308.13 \pm 60.28 \mathrm{MPa}$, respectively) when compared with the unseeded PRFM control $(1.3 \pm 1.99 \mathrm{MPa} ; \mathrm{p}=0.003)$. No differences were found between the two MSC types $(\mathrm{p}=0.99)$. The elastin slope showed a significant increase after incubation with cells; this might be due to cell to cell interactions through the cytoskeleton [23]. A previous study on keratinocytes co-cultured with fibroblasts in fibrin and collagen constructs reported alterations in cell proliferation, contraction and elastic modulus [24]. A lower cell number led to less contraction and mechanical strength of the constructs. Co-culture of keratinocytes and fibroblasts in fibrin gel increased the keratinocyte number [25]

In the present study, the collagen slope and the stiffness of the PRFM showed no differences when cultured with or without cells, although the collagen slope was slightly higher for the hBM-MSC seeded than for the hUC-MSC seeded and unseeded PRFM groups $(107.87 \pm 49.9$ $\mathrm{MPa}$ vs $41.934 \pm 31.33 \mathrm{MPa}$ and $54.79 \pm 50.37 \mathrm{MPa}$, respectively). When aligned with the collagen slope, the PRFM matrix seeded with hBM-MSC showed a slightly greater stiffness when compared with the hUC-MSC seeded and unseeded PRFM $(120.29 \pm 42.46 \mathrm{MPa}$ vs $47.45 \pm 29.29 \mathrm{MPa}$ and $57.79 \pm 60.92 \mathrm{MPa}$, respectively). This lack of a difference indicated that the cells in the PRFM had not yet generated ECM after $24 \mathrm{~h}$ incubation, as collagen is the main fibre that directs the tensile strength [26]. The failure to find a difference may also reflect the analysis of too small a number of samples in each group, as the deviation in each analysis was very broad.

The findings in this study contrast with previous reports of an enhancement of matrix strength by cells embedded in a fibrin gel due to myosin-driven cell contraction [27]. One possible explanation is that the cells in the PRFM occupied only the matrix surface after $24 \mathrm{~h}$, and had not yet penetrated the whole matrix. A hematoxylin/eosin ( $\mathrm{H}$ and $\mathrm{E}$ ) staining study should be conducted to investigate this. Another possibility is that static incubation precludes the mechanical sensing necessary for the regeneration process. Fibroblasts are believed to perceive mechanical loading signals from cellular biological events via the cytoskeleton, and the signals are transferred and converted in the nucleus to initiated expression of ECM components, such as collagen [28]. For example, cyclic strains increase collagen synthesis in tendons via this mechanism [29]. This possibility will require further studies involving collagen quantification and mRNA expression.

Matrix stiffness directs the differentiation of MSC. For example, incubation of UC-MSC with polyacrylamide gels coated with fibronectin with differing stiffness (Young's modulus: $13-16 \mathrm{kPa}, 35-$ $38 \mathrm{kPa}, 48-53 \mathrm{kPa}$ and $62-68 \mathrm{kPa}$ ) resulted in adipogenesis at low stiffness and increases in myogenicity markers (e. g. desmin and MOYG) at higher stiffness $(48-53 \mathrm{kPa})(\mathrm{p}<0.05)$. The stiffest matrix drove MSC differentiation into osteogenesis, via the expression of ALP, collagen type I, osteocalcin and Runx2 [30]. In the present study, a layer of cells was detected on the surface of the PRFM using SEM, and the surface showed a gradual thickening. Direct seeding of hBM-MSC and hUC-MSC increased the foggy appearance of the cell layer at the surface of the PRFM, as indicated by SEM imaging. This might be evidence of thickening of the cell layer on the surface of PRFM.

\section{CONCLUSION}

The stiffness of the PRFM was significantly improved by incubation with hBM-MSCs or hUC-MSCs. Although the matrix degradation was very high, PRFM showed favorable potential as a vehicle for hBM-MSC administration to facilitate wound healing. Further study is needed to improve matrix integrity for the application of PRFM as a scaffold.

\section{ACKNOWLEDGEMENT}

We thank the University of Indonesia, for funding support (Grant no 2101/UN3. R3.1/HKP.05.00/2018). This article was presented in the $4^{\text {th }}$ International Conference and Exhibition on the Indonesian Medical Education and Research Institute (ICE on IMERI 2019), 
Faculty of Medicine, Universitas Indonesia. We thank the $4^{\text {th }}$ ICE on IMERI committee who had supported the peer review and manuscript preparation before submitting to the journal.

\section{FUNDING}

Nil

\section{AUTHORS CONTRIBUTIONS}

All authors have contributed equally.

\section{CONFLICT OF INTERESTS}

All authors have none to declare.

\section{REFERENCES}

1. Harper MT, MacCarthy Morrogh L, Jones ML, Konopatskaya O, Poole AW. Platelets: their role in atherogenesis and thrombosis in coronary artery disease. Edited by Sarah Jane George; 2010.

2. Litvinov RI, Weisel JW. Fibrin mechanical properties and their structural origins. Matrix Biol 2017;60-61:110-23.

3. Lin F, Zhu J, Tonnesen MG, Taira BR, McClain SA, Singer AJ, et al. Fibronectin peptides that bind PDGF-BB enhance survival of cells and tissue under stress. J Invest Dermatol 2014;134:1119-27.

4. Scarano A, Ceccarelli M, Marchetti M, Piattelli A, Mortellaro C. Soft tissue augmentation with autologous platelet gel and $\beta$ TCP: a histologic and histometric study in mice. BioMed Res Int 2016. https://doi.org/10.1155/2016/2078104

5. Reksodiputro M, Widodo D, Bashiruddin J, Siregar N, Malik S. PRFM enhance wound healing process in the skin graft. Facial Plast Surg 2014;30:670-5.

6. Engler AJ, Sen S, Sweeney HL, Discher DE. Matrix elasticity directs stem cell lineage specification. Cell 2006;126:677-89.

7. Law JX, Chowdhury SR, Saim AB, Idrus RBH. Platelet-rich plasma with keratinocytes and fibroblasts enhance the healing of full-thickness wounds. J Tissue Viability 2017;26:208-15.

8. Zhang GA, Ning FG, Zhao NM. Biomechanical properties of four dermal substitutes. Chin Med J 2007;120:1454-5.

9. Sandora N. Regeneration of the decellularised tendon by human mesenchymal stem cells in response to uniaxial tensile strain. University of Leeds; 2016.

10. Italiano JE, Bergmeier $\mathrm{W}$, Tiwari $\mathrm{S}$, Falet $\mathrm{H}$, Hartwig $\mathrm{JH}$ Hoffmeister KM, et al. Mechanisms and implications of platelet discoid shape. Blood 2003;101:4789-96.

11. Sandora N, Fisher J, Ingham E. Decellularisation process to produce graft for transplantation; repopulation capacity of human MSCS. Adv Sci Lett 2018;24:6497-501.

12. Moran P, Coats B. Biological sample preparation for SEM imaging of porcine retina. Microscopy Today 2012;20:28-31.

13. Guthold M, Liu W, Sparks E, Jawerth L, Peng L, Falvo M, et al. A comparison of the mechanical and structural properties of fibrin fibers with other protein fibers. Cell Biochem Biophys 2007;49:165-81.

14. Chester D, Brown AC. The role of biophysical properties of provisional matrix proteins in wound repair. Matrix Biol 2017;60-61:124-40.
15. Badylak SF, Freytes DO, Gilbert TW. Extracellular matrix as a biological scaffold material: structure and function. Acta Biomaterialia 2009;5:1-13.

16. Cheng CW, Solorio LD, Alsberg E. Decellularized tissue and cellderived extracellular matrices as scaffolds for orthopaedic tissue engineering. Biotechnol Adv 2014;32:462-84.

17. Kim YJ, Seo DH, Lee SH, Lee SH, An GH, Ahn HJ, et al. Conditioned media from human umbilical cord blood-derived mesenchymal stem cells stimulate rejuvenation function in human skin. Biochem Biophys Reports 2018;16:96-102.

18. Hasan MH, Botros KG, El-Shahat MA, Abdallah HA, Sobh MA. In vitro differentiation of human umbilical cord blood mesenchymal stem cells into functioning hepatocytes. Alexandria J Med 2017;53:167-73.

19. Vinaya Kumar R, Shubhashini N. Platelet-rich fibrin: a new paradigm in periodontal regeneration. Cell Tissue Banking 2013;14:453-63.

20. Babo P, Santo VE, Duarte ARC, Correia C, Costa MH, Mano JF, et al Platelet lysate membranes as new autologous templates for tissue engineering applications. Inflammation Regener 2014;34:33-44.

21. Furst W, Banerjee A, Redl H. Comparison of structure, strength and cytocompatibility of a fibrin matrix supplemented either with tranexamic acid or aprotinin. J Biomed Mater Res Part B 2007;82:109-14.

22. Briquez PS, Lorentz KM, Larsson HM, Frey P, Hubbell JA Human kunitz-type protease inhibitor engineered for enhanced matrix retention extends the longevity of fibrin biomaterials. Biomaterials 2017;135:1-9.

23. Chopin Doroteo M, Salgado Curiel RM, Perez Gonzalez J, Marin Santibanez BM, Krötzsch E. Fibroblast populated collagen lattices exhibit opposite biophysical conditions by fibrin or hyaluronic acid supplementation. I Mechamical Behavior Biomed Materials 2018;82:310-9.

24. Lai VK, Frey CR, Kerandi AM, Lake SP, Tranquillo RT, Barocas $\mathrm{VH}$. Microstructural and mechanical differences between digested collagen-fibrin co-gels and pure collagen and fibrin gels. Acta Biomaterialia 2012;8:4031-42.

25. Montalbano G, Toumpaniari S, Popov A, Duan P, Chen J Dalgarno K, et al. Synthesis of bioinspired collagen/alginate/fibrin-based hydrogels for soft tissue engineering. Materials Sci Eng: C 2018;91:236-46.

26. Kadler K, Holmes D, Trotter J, Chapman J. Collagen fibril formation. Biochem J 1996;316:1-11.

27. Jansen Karin A, Bacabac Rommel G, Piechocka Izabela K Koenderink Gijsje H. Cells actively stiffen fibrin networks by generating contractile stress. Biophysical J 2013;105:2240-51.

28. Wang JHC, Thampatty BP, Lin JS, Im HJ. Mechanoregulation of gene expression in fibroblasts. Gene 2007;391:1-15.

29. Screen HRC, Shelton JC, Bader DL, Lee DA. Cyclic tensile strain upregulates collagen synthesis in isolated tendon fascicles. Biochem Biophysical Res Communications 2005;336:424-9.

30. Xu J, Sun M, Tan Y, Wang H, Wang H, Li P, et al. Effect of matrix stiffness on the proliferation and differentiation of umbilical cord mesenchymal stem cells. Differentiation 2017;96:30-9. 